\title{
Atopic Dermatitis and the Quality of Life in Children, Adolescents and Their Families
}

\author{
Nermine H. Eleishi MD'1, Lubna M. Fawaz MD ${ }^{2}$, Eman E. Sedik MD², \\ ${ }^{1}$ Dermatology Department, Faculty of Medicine, Cairo University \\ ${ }^{2}$ Pediatrics Department, Faculty of Medicine, Cairo University \\ ${ }^{3}$ Family Medicine, Faculty of Medicine, Cairo University \\ * The corresponding author
}

\begin{abstract}
Background:Atopic dermatitis (AD) is a pruritic disease that usually starts in early infancy with an international prevalence rate of $15-30 \%$ in children and $2-10 \%$ in adults. Measuring the impact of $\mathrm{AD}$ on the quality of life is very useful as it allows patients to express their feelings and appreciate their physicians' concerns. It improves doctor-patient communication and helps in disease management.
\end{abstract}

Objective: A cross sectional observational study that was conducted aimed to determine the effect of atopic dermatitis on the quality of life among children and adolescents attending dermatology outpatient clinics at Kasr Al Ainy hospital and Pediatric specialized hospital, during the period from November 2015 to June 2016.

Methods:A sample of 400 children, adolescents and their families were included in the study. They were asked to fill the QOL questionnaires (Children Dermatology Life Quality Index (CDLQI), Dermatology Life Quality Index (DLQI) and Dermatitis Family Impact questionnaire (DFI).

Results:Results of the study showed that $48 \%$ of AD patients aged (6-16) has very large effect on QOL, $47.3 \%$ have extremely large effect and $4.8 \%$ have moderate effect while $52 \%$ of AD patients aged (16-18) has extremely large effect on QOL and $47 \%$ have very large effect. Families of AD patients have very large effect on QOL where $44 \%$ have extremely large effect.

Conclusion:This study concluded that AD has a negative impact on the QOL of children, adolescent and their families irrespective to socio-demographic and socioeconomic factors.

Key words: Atopy, life quality, Impact 


\section{Introduction:}

Atopic dermatitis (AD) is a chronic inflammatory pruritic skin disease that usually starts in childhood and early adolescence. (1) Mostly, atopic dermatitis starts before the age of five years with slight female to male predominance (1.3 to 1$)$.(2) The prevalence of AD has increased for unknown reason; however it is believed that environmental factors, pollutants, exposure to allergies are the main causes of this increase. (3) The latest prevalence for AD showed that $5-20 \%$ of children are affected worldwide.(4)

There are multiple risk factors for atopic dermatitis mainly a positive family history of atopy.(5) Early day care, farm animal, pets in early life and the excessive use of broad-spectrum antibiotics may be risk factors due to a general increase in exposure to non-pathogenic microbes.(6) Food allergy could be association or an exacerbating factor for AD.(7)

There are three age-group stages of atopic dermatitis: infantile (infancy to 2 years old) present as lesions on the extensor surfaces and cheeks or scalp, childhood (2 to 12 years old) present as lichenified plaques in a flexural distribution, and the adult stage (older than 12 years) present as thickened skin mostly over the face, wrists and forearms. (8) Atopic dermatitis can present in three clinical phases, acute phase presents with a vesicular, weeping, crusting eruption, sub-acute phase presents with dry, scaly, erythematous papules and plaques and the chronic phase which is usually associated with lichenification from repeated scratching.(9)

The criteria for diagnosing atopic dermatitis are published by the United Kingdom working group on atopic dermatitis with the aim of developing a minimum list of reliable discriminators for atopic dermatitis.(10) The published criteria include one mandatory and at least three of five majo criteria. The mandatory criterion is the evidence of pruritic skin, including the report by a parent of a child rubbing or scratching while the major criteria are history of skin creases being involved, history of asthma or hay fever, the presence of generally dry skin within the past year, symptoms beginning in a child before the age of two years and/or visible dermatitis involving flexural surfaces.(10)

The optimal management of atopic dermatitis requires an approach that involves the elimination of exacerbating factors, restoration of the skin barrier function and hydration of the skin, patient education, and pharmacologic treatment of skin inflammation.(11) Many patients with atopic dermatitis can initially be treated by a family physician. Patients should be referred to a specialist (e.g., dermatologist, allergist) when the diagnosis is uncertain, inadequate response to the appropriate therapy and if treatment with systemic immunosuppressive agents is being considered.(12)

Topically applied corticosteroids and emollients are the mainstay of therapy for atopic dermatitis. Topical corticosteroids are applied one or two times per day for 2-4 weeks. Emollients should be used multiple times per day in association with topical corticosteroids.(13) Oral antihistamines may be beneficial in the setting of sleep loss secondary to itch, but should not be substituted for management of AD with topical therapies.(14)

Health related quality of life (HRQOL) is the capacity to perform the usual activities for a person's age and social life.(15) It measures the impact of chronic diseases on the patient's and their families' lives. Over
$25 \%$ of children with AD suffered continuous eczema associated with moderate to severe HRQOL impairment.(16) In comparison with other chronic diseases, it was found that parents rated moderate to severe eczema as worse for the child than having diabetes and similar to having asthma.(17) It has a major effect on the life of the patient's family through limitation of family diet, eating out, pet ownership and avoidance of certain household products such as soaps and perfumed products. Negative comments from others about fear of contagion or the child's appearance also cause great distress and blame is often felt to be apportioned by spouses or relatives (18).

\section{Methods:}

This study is a cross sectional observationa study that was done using El-Gilany Questionnaire and its Arabic version to assess socio-economic status, Children's Dermatology Life quality index (CDLQI), Dermatology life quality index (DLQI) and Dermatitis family impact (DFI) to determine the effect of atopic dermatitis on the quality of life among 400 of children and adolescents as well as their families who were attending dermatology outpatient clinics at Kasr Al Ainy hospital and Pediatric specialized hospital, on 3 working days per week for 7 months from November 2015 to June 2016.

The sample size was calculated with $95 \%$ Confidence Interval using Epi-Info version. The sample size was 400 participants (children and adolescents).(3) The included participants aged 6 to 18 years old diagnosed with atopic dermatitis according to U.K Working Party's Diagnostic Criteria. The excluded participants were those having any factor that may affect the quality of life e.g. chronic disease or used any relief med- ication 1 week prior to the study.

The study passed through three phases:

Phase 1: Administrative issues: for protoco revision and ethical approval by the family medicine department, faculty of medicine and Cairo university.

Phase 2: Construction of the study tools and preparing the questionnaires which are

1. El-Gilany Questionnaire and its Arabic version: This scale includes 7 domains with a total score of 84 , with a higher score indicating better SES. It is validated too19) 2. Children's Dermatology Life Quality Index and its Arabic version (CDLQI) for children aged 6-16 years. It is self-explanatory composed of 10 questions. It is usually completed in one to two minutes.

Each question has four alternative responses: "not at all", a "little", a "quite a lot", or "very much" with $0,1,2$ and 3 scores respectively. The CDLQI was calculated by summing the score of questions, resulting in a maximum of 30 and minimum of zero. The higher the score the greater the impairment of life quality. All the questions referred to the preceding week. It is validated tool $(20)$

3. Dermatology Life Quality Index (DLQI) and its Arabic version for patients above the age of 16. It is self-explanatory 10 questions questionnaire and is usually completed in one to two minutes. The DLQI was calculated by summing the score of questions, resulting in a maximum of 30 and minimum of zero. The higher the score,

the greater impairment of quality of life. It is validated tool. (21)

4. Dermatitis Family Impact Questionnaire (DFI) and its Arabic version for the families of the above mentioned 2 groups. DFI consists of simple 10 questions, usually filled in 2 minutes. Each question was assigned a score from 0 to 3 with the zero score indicated no influence and score 30 indicated the highest impairment of the function. It is validated tool. (22) 
The approval to use these questionnaires performed using the Statistical Package was taken by an email from the authors. for Social Sciences (SPSS) version 21. NuPhase 3: Field work (implementation) merical data were summarized using means phase: A structured patient interview was and standard deviations or medians and done that took 15 minutes included screen- ranges. Categorical data were summarized ing for readiness to participate in the study/ as percentages. Comparisons between the 2 informed consent, full history taking, phys- groups with respect to normally distributical examination and filling the question- ed numeric variables were done using the naires.

Phase 4: Data management and statistical groups (SES) done with univariate ANOVA analysis: All collected questionnaires were test. Correlations were determined by using revised for completeness. Then the collect- Pearson's test. P value of $\leq 0.05$ was consided data were coded and entered on the com- ered statistically significant.

puter using spread sheet "Microsoft Of- The mean age of the study participants was fice Excel Software" program, 2007. Data $8.5 \pm 2.9$ with $(51.5 \%)$ were females and management and statistical analysis were mostly living in urban areas $(60.5 \%)$. The

\section{Results:}

Table (1): Socio-demographic characteristics of the study participants

\begin{tabular}{|l|l|c|c|}
\hline Socio-demographic characters & \multicolumn{2}{|c|}{ No. } & \% \\
\hline \multirow{5}{*}{ Age (years) } & Mean \pm SD & \multicolumn{2}{|c|}{$8.5 \pm 2.9$} \\
\cline { 2 - 4 } & Range & 321 & 80.3 \\
\cline { 2 - 4 } & Childhood 6-10 & 42 & 10.5 \\
& Early adolescent 10-13 & 14 & 3.5 \\
& Mid adolescent 14-15 & 23 & 5.7 \\
\hline Gender & Late adolescent 16-18 & 194 & 48.5 \\
& Male & 206 & 51.5 \\
\hline Residency & Female & 158 & 39.5 \\
& Rural & 242 & 60.5 \\
\hline Score=84 & Urban & 4 & 1.0 \\
& Very Low (score $\leq 21)$ & 312 & 78.0 \\
& Low (score 22-42) & 79 & 19.8 \\
& Moderate ( 43-63) & 5 & 1.3 \\
\hline
\end{tabular}

socioeconomic status according to El Gilany questionnaire was low in $(78 \%)$ while high status was found in only $(1.3 \%)$.

The children aged (6-16 years) are categorized according Children's Dermatology Life Quality Index (CDLQI) as addressed

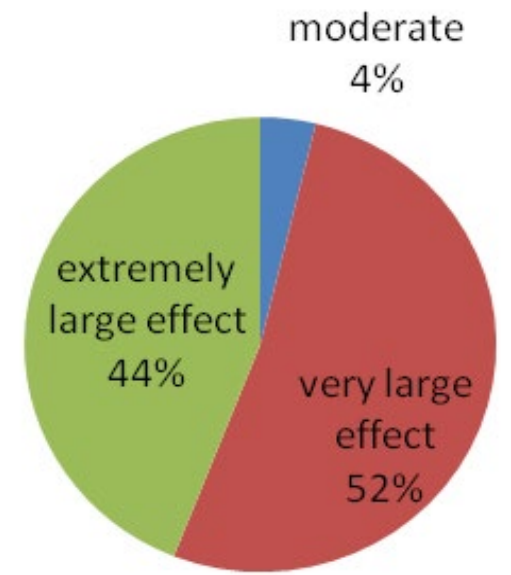

Figure (1): Classification according to Children

Der matology Life Quality Index total score

The children aged >-16 years are catego- have extremely large effect and 3\% have rized according Dermatology Life Quality moderate effect according to Dermatitis Index (DLQI) as addressed in Figure (2). Family Impact Questionnaire (DFI). Table It shows that $52 \%$ of AD patients have ex- (2) shows that there is a significant positive tremely large effect on QOL. On the other correlation between CDLQI score and DFI hand, 47\% have very large effect. Figure (3) score (P value 0.001 ). However there is no demonstrates that $52 \%$ of $\mathrm{AD}$ patients fam- correlation between quality of life and the ilies have very large effect on QOL, 44\% socio-economic status.

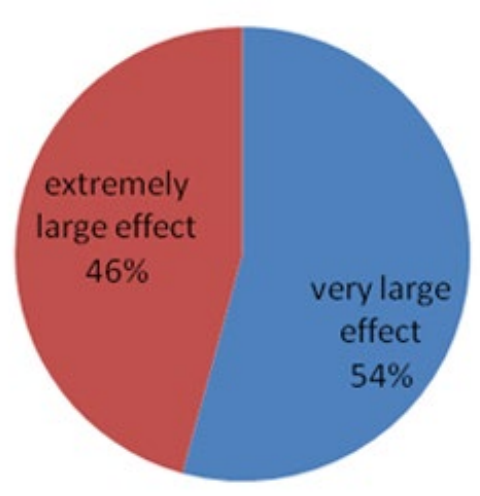

Fig (2): Classification according to DLQI

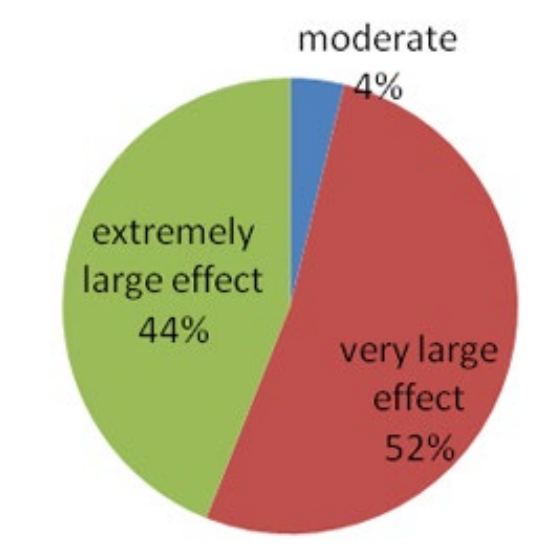

in figure (1). It shows that; $48 \%$ of children Dave very large effect on QOL, $47.3 \%$ have extremely large effect and $4.8 \%$ have moderate effect.

Fig (3): Classification of QOL according to DFI 


\section{Table (2): Correlation between CDLQI score and DFI score}

\begin{tabular}{|c|c|c|c|c|c|}
\hline & & Age & \begin{tabular}{|c|} 
Duration \\
of disease
\end{tabular} & $\begin{array}{l}\text { SES } \\
\text { score }\end{array}$ & $\begin{array}{l}\text { CDLQI } \\
\text { SCORE }\end{array}$ \\
\hline \multirow{2}{*}{ Duration of disease } & $\mathrm{R}$ & $.462 * *$ & & & \\
\hline & P value & $<0.001$ & & & \\
\hline \multirow{2}{*}{ SES score } & $\mathrm{R}$ & .008 & .039 & & \\
\hline & $\mathrm{P}$ value & .866 & .434 & & \\
\hline \multirow{2}{*}{ CDLQI SCORE } & $\mathrm{R}$ & .086 & .090 & .026 & \\
\hline & $\mathrm{P}$ value & .085 & .071 & .598 & \\
\hline \multirow{2}{*}{ DFI SCORE } & $\mathrm{R}$ & .007 & .084 & -.085 & $.473 * *$ \\
\hline & P value & .890 & .095 & .090 & $<0.001$ \\
\hline
\end{tabular}

\section{Discussion:}

In the present study, the majority of the patients were of low socioeconomic status (78\%). In contrast, Al Shobaili (23) study which was conducted at Qassim region in Saudi Arabia and aimed to clarify the impact of childhood atopic dermatitis on family life, found that most of $\mathrm{AD}$ patient were of intermediate socioeconomic state $(63.5 \%)$.This difference is mostly attributed to the fact that most patients who came to Kasr Al Ainy hospital are of low SES.

In the current study, $\mathrm{AD}$ had large effect on QOL in children where $48 \%$ of the patients and $47.3 \%$ considered extremely large effect. In contrast, Amaral et al(24) which was conducted at Brazil found that $38 \%$ of the patients had moderate effect on QOL and $34 \%$ had very large effect on QOL.

The current study stated that $47 \%$ of the $\mathrm{AD}$ adolescent patients had large effect on QOL and 52\% considered extremely large effect. A study done by Sanchez et al(25) throughout Spain indicated that AD had a very large effect in $27.1 \%$, and an extremely large effect in $2.6 \%$.

The present study showed that $52 \%$ of AD patients, families had very large effect on

\section{Study limitations:}

-The adolescent participants of the study were much more less than the children group.

- The absence of a score for the severity of atopic dermatitis and comparing it with the quality of life in patients and their families

\section{References:}

1- Carlsten C, Dimich-Ward H, Ferguson A et al (2013). Atopic dermatitis in a high-risk cohort: natural history associated allergic outcomes, and risk factors. Ann Allergy Asthma Immunol 77(4), 316-321. Available on www.ncbi.nlm.nih.gov. Accessed on December 2015.

2- Kang K, Polster AM, Nedorost St. (2003). Atopic dermatitis. In: Dermatology, Mosby, New York 2003. p.199. Available on www.uptodate.com / contents/pathogenesis - clinical - manifestations - and - diagnosis - of - atopic - dermatitis - eczema Accessed in November 2015

3- Torres-Borrego J, Molina-Teran A, Montes-Mendoza C. (2008) Prevalence and associated factors of allergic rhinitis and atopic dermatitis in children. Allergol Immunopathol (Madr)12 (7) 231-234. Available on www.ncbi.nlm.nih.gov. Accessed on January 2016.

4- Shaw T, Currie G, Koudelka C, et al (2011). Eczema prevalence in the United States: data from the 2003 National Survey of Children's Health. Journal of Investigative Dermatology. 1;131(1):67-73. Available on www.ncbi.nlm.nih.gov. Accessed on February 2016

5- $\quad$ Irvine D, Irwin M, Leung D. (2011). Filaggrin mutations associated with skin and allergic diseases. New England Journal of Medicine 365.14, 1315-1327. Available on www.nejm.org. Accessed on February 2016.
6- $\quad$ Flohr C, Yeo L. (2011). Atopic dermatitis and the hygiene hypothesis revisited. Curr Probl Dermatol 41:1-34 Available on www.ncbi.nlm.nih.gov. Accessed on January 2016.

7- $\quad$ Suh K (2010). Food allergy and atopic dermatitis: separating fact from fiction. Semin Cutan Med Surg; 29: 72-78. Available on www.ncbi.nlm.nih.gov. Accessed on January 2016.

8- Park M, Park K, Li K, et al (2013). The short stature in atopic dermatitis patients: are atopic children really small for their age. Annals of dermatology, 25(1) 23-27. Available on www.ncbi.nlm.nih.gov. Accessed on March 2016.

9- Berke R, Singh A, Guralnick M. (2012). Atopic dermatitis: an overview. American family physician, 86(1), 35-42. Available on www.aafp.org. Accessed on January 2016.

10- Williams H (2005) Clinical practice. Atopic dermatitis. N Engl J Med; 352:2314.

Available on www.nejm.org. Accessed on January 2016.

11- Tollefson M, Bruckner A. (2014) Section on Dermatology. Atopic dermatitis: skin-directed management. Pediatrics; 134:e1735. Available on pediatrics.aappublications.org. Accessed on February 2016. 12- Krakowski A, Eichenfield L, Dohil M (2008).Management of atopic dermatitis in the pediatric population. Pediatrics, 122(4):812-24. Available on pediatrics. aappublications.org. Accessed on February 2016.

13- Simpson E, Chalmers J, Hanifin J, et al (2014). Emollient enhancement of the skin barrier from birth offers effective atopic dermatitis prevention. Journal of Allergy and Clinical Immunology, 134(4), 818-823. Available on www.ncbi.nlm.nih.gov. Accessed on March 2016. 
14- Sidbury R, Davis D, Cohen D, et al practical use. Br J Dermatol; 132: 942_9. (2014). Guidelines of care for the manage- Available on www.ncbi.nlm.nih.gov. Acment of atopic dermatitis: section 3. Man- cessed on December 2015.

agement and treatment with phototherapy 21- Finlay A, Khan G. (1994). Dermatoland systemic agents. Journal of the American Academy of Dermatology, 71(2), 327349. Available on www.ncbi.nlm.nih.gov Accessed on March 2016.

15- Annett R, Bender B, Lapidus J, et al. (2001). Predicting children's quality of life in an asthma clinical trial: what do children's reports tell us? J Pediatr, 139: 854 61. Available on www.jpeds.com. Accessed on January 2016.

16- Emerson R, Charman C, Williams $\mathrm{H}$ (2000). The Nottingham Eczema Severity Score: preliminary refinement of the Rajka and Langeland grading. Br J Dermatol 142: 288-97. Available on www.ncbi.nlm.nih. gov. Accessed on December 2015.

17- Beattie P, Lewis-Jones M. (2006). A comparative study of impairment of Quality Of Life (QOL) in children with skin disease and children with other chronic childhood diseases. Br J Dermatol 155: 145-55. Available on www.ncbi.nlm.nih.gov. Accessed on December 2015.

18- Chamlin S, Frieden I, Williams M, et al (2004). Effects of atopic dermatitis on young American children and their families. Pediatrics 114: 607-11. Available on pediatrics.aappublications.org. Accessed on February 2016.

19- El-Gilany A, El-Wehady A, El-Wasify M. (2012). Updating and validation of the socioeconomic status scale for health research in Egypt. Eastern Mediterranean Health Journal, 18(9), 962.) Available on www.who.int/iris. Accessed on November 2015.

20- Lewis -Jones M, Finlay A. (1995). The Children's Dermatology Life Quality Index $\left(\mathrm{CDLQI}^{\mathrm{a}}\right)$ : initial validation and ogy Life Quality Index (DLQI): A simple practical measure for routine clinical use. Clinical and Experimental Dermatology, 19: 210-216. Available on www.ncbi.nlm nih.gov. Accessed on December 2015.

22- Lawson V, Lewis-Jones M , Finlay A ,et al. (1998). The family impact of childhood atopic dermatitis: the Dermatitis Family Impact questionnaire. Br J Dermatol, 138: 107-113. Available on www.ncbi nlm.nih.gov. Accessed on December 2015. 23- Al Shobaili (2010). The impact of childhood atopic dermatitis on the patients family. Pediatric dermatology, 27(6), 618 623. Available on onlinelibrary.wiley.com. Accessed on April 2016.

24- Amaral C, March M, Sant'Anna C (2012). Quality of life in children and teenagers with atopic dermatitis. Anais brasileiros de dermatologia, 87(5), 717-723. Available on www.ncbi.nlm.nih.gov. Ac-

25- Sánchez-Pérez J, Daudén-Tello E, Mora A,et al. (2013). Impact of atopic dermatitis on health-related quality of life in Spanish children and adults: the PSEDA study. Actas Dermo-Sifiliográficas (English Edition), 104(1), 44-52.] available on www. actasdermo.org/en. Accessed on april 2016. cessed on April 2016.
الالنم الهزبى

التهاب الجلد التأتبى وجودة الحياة لدى الاطفال والمر اهقين وعائلاتهم

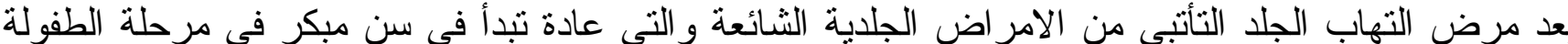

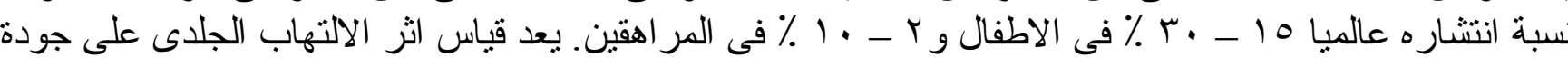

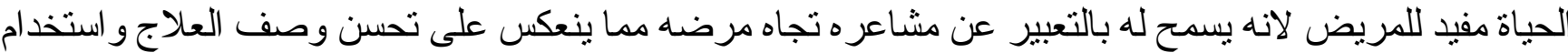

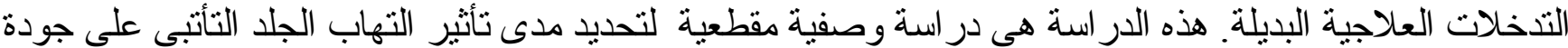

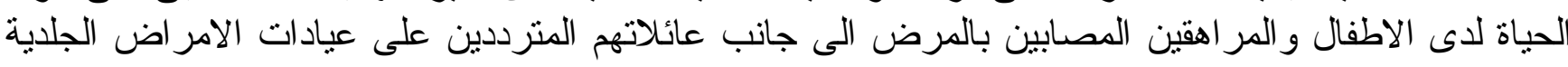

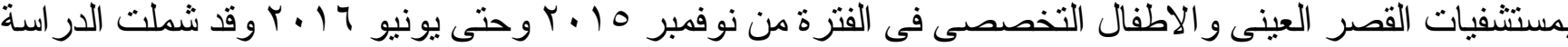

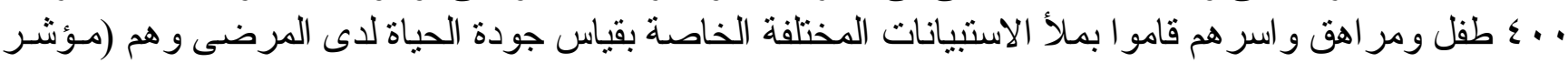

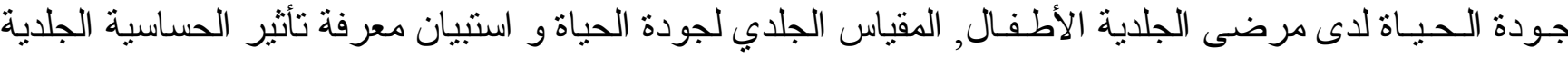

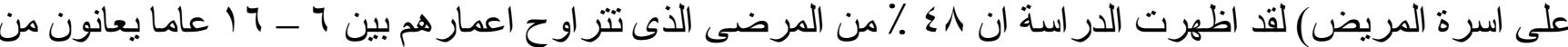

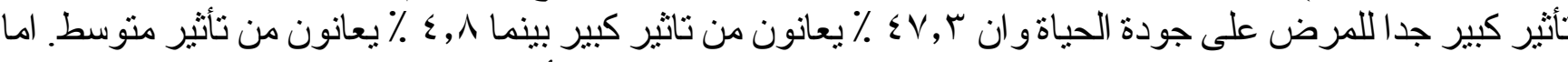

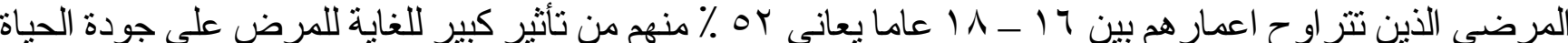

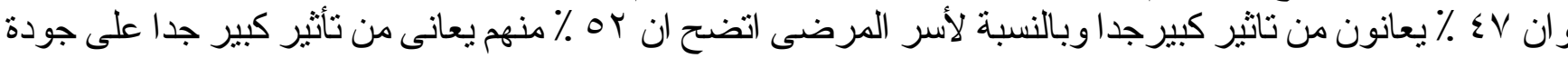

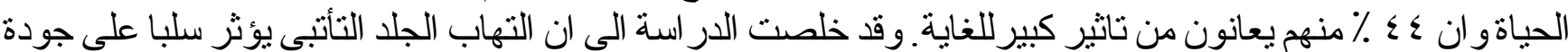

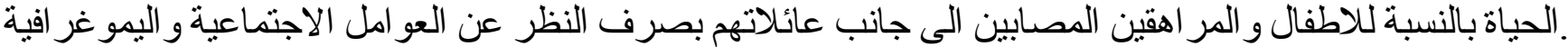

